\title{
CFD Study on Selective Catalytic Reduction of 660MW Unit
}

\section{Zhao Dazhou $^{\mathrm{a}}$, He Sheng ${ }^{\mathrm{b}}$ and Zheng Wenguang ${ }^{\mathrm{c}}$}

Huadian Electric Power Research Institute, Zhejiang, Hangzhou,310030,China;

asseudzz@126.com, bsheng-he@chder.com, cwenguang-zheng@chder.com

Keywords: selective catalytic reduction; detailed reaction kinetics; specific surface area; ammonia injection strategy

\begin{abstract}
A three-dimensional SCR reactor model of 660MW coal fired unit was established by using FLUENT coupled detailed reaction kinetics. The effect of different ammonia injection strategies and the specific surface area of catalyst on the denitrification reaction were studied by the model. The results show that: for the catalysts just putting into operation, denitrification reaction was mainly accomplished in the first layer catalyst, the second layer catalyst mainly plays a role in the absorption of ammonia. The effect of denitrification was the same whether using 30 zones ammonia injection strategy or using 10 zones ammonia injection strategy. When SCR catalysts were putting into operation after a period of time, as the first layer catalyst has the problem of plug and wear, the denitrification efficiency was reduced and the ammonia slip was increased. At this point, the effect of 30 zones ammonia injection strategy was slightly better than 10 zones ammonia injection strategy.
\end{abstract}

\section{Introduction}

$\mathrm{NO}_{\mathrm{x}}$ is one of the major pollutant sources for atmosphere, and it is a threat to environment. SCR (Selective Catalytic Reduction) flue gas denitrification technology has been widely used in coal fired power plants due to it's high denitrification efficiency and technical maturity ${ }^{[1]}$. For SCR, the excellent performance of catalysts and the reasonable distribution of both velocity and component in reactor are the key to obtain high $\mathrm{NO}_{\mathrm{x}}$ removal efficiency ${ }^{[2]}$.

As the coal quality and unit load are variable, therefore, there are many problems of SCR in the actual engineering operation. Numerical simulation has been widely used in the design and optimization of SCR system because of the advantages of high efficiency, fast and convenient. The traditional numerical simulation techniques are mostly aimed at the flow field and the distribution of the components in SCR reactor ${ }^{[3-4]}$, and lack of simulation study on chemical reaction, also the simulation study on chemical reaction are mostly based on $\mathrm{NH}_{3} / \mathrm{NO}$ ratio above $1^{[5-7]}$, so the models have some limits.

With the further development of numerical simulation technology, CFD coupled with detailed reaction kinetics to simulate flow processes with complex chemical reactions is used in practical engineering application more and more, this method has no restriction on the condition of $\mathrm{NH}_{3} / \mathrm{NO}$ ratio, so the model is more practical.

A three-dimensional model was established by FLUENT coupled with SCR detailed reaction kinetics, in this paper. The effect of different ammonia injection strategies and catalyst specific surface area on the denitrification reaction was studied, finally providing a reference for practical engineering operation.

\section{Reactor Model}

\subsection{Geometric Model}

Taken a certain SCR system of 660MW power station as the research object, the boiler uses a double SCR reactor in parallel, 2+1 layout used for catalyst, 2 layer catalysts were installed and the 
upper layout was spare layer, the catalyst form is plate type, and it's parameters are shown in table 1. The CFD geometric model was established based on SCR construction drawings proved by power plant, the model is shown in figure 1. It was meshed by GAMBIT, the total grid number of the model is about 7 million.

Tab.1 parameters of catalyst

\begin{tabular}{ccc}
\hline parameter & unit & value \\
\hline specific surface area $/ a_{m}$ & $\mathrm{~m}^{-1}$ & 299 \\
voidage $/ \varepsilon$ & - & 0.87 \\
size of each module & $\mathrm{m} \times \mathrm{m} \times \mathrm{m}$ & \\
$($ length $\times$ width $\times$ hight $)$ & & $1.882 \times 0.954 \times 1.360$ \\
size of reactor section & $\mathrm{m} \times \mathrm{m}$ & $16.22 \times 10.5$ \\
\hline
\end{tabular}

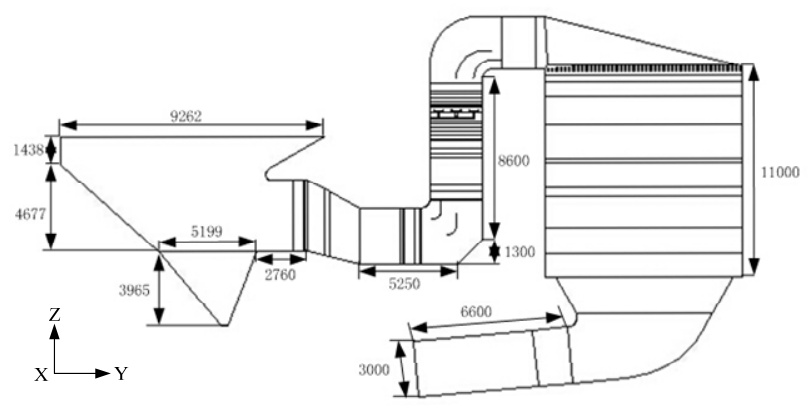

(a) the main dimension of the reactor $(\mathrm{mm})$

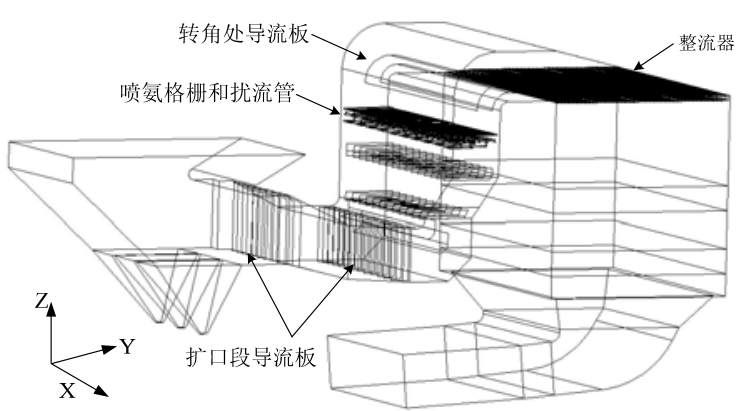

(b) internal structure of the reactor

Fig.1 schematic diagram of the reactor
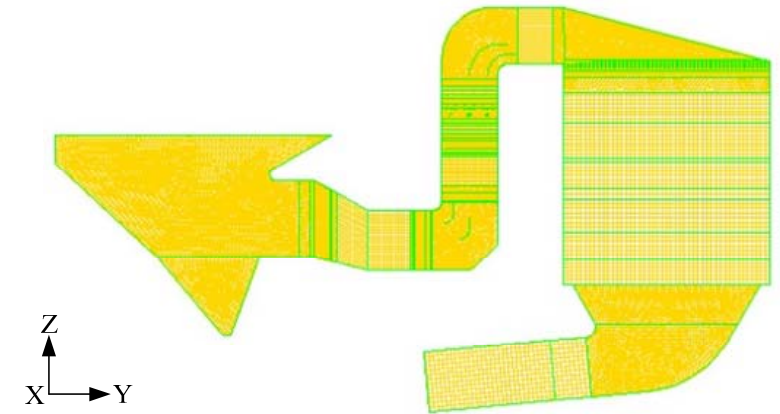

Fig.2 Grid division of the reactor

\subsection{Detailed kinetics of SCR}

According to relevant literature research[8-9], catalytic reduction of $\mathrm{NO}_{\mathrm{x}}$ at the surface of vanadium catalyst includes 6 steps, 12 species, the schematic diagram of the reaction process is shown in figure 3.

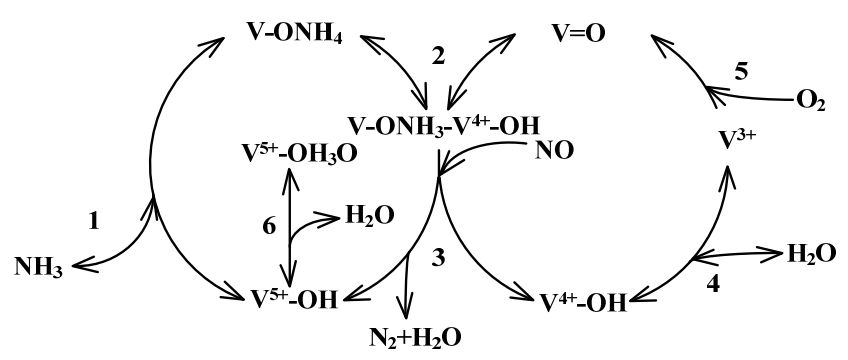

Fig.3 schematic diagram of reaction process

6 steps reaction can be expressed as:

$$
\begin{aligned}
& \mathrm{NH}_{3}+\mathrm{V}^{5+}-\mathrm{OH} \rightleftharpoons \mathrm{V}-\mathrm{ONH}_{4} \\
& \mathrm{~V}-\mathrm{ONH}_{4}+\mathrm{V}=\mathrm{O} \rightleftharpoons \mathrm{V}_{-}-\mathrm{ONH}_{3}-\mathrm{V}^{4+}-\mathrm{OH}
\end{aligned}
$$




$$
\begin{gathered}
\mathrm{NO}+\mathrm{V}-\mathrm{ONH}_{3}-\mathrm{V}^{4+}-\mathrm{OH} \rightarrow \\
\mathrm{N}_{2}+\mathrm{H}_{2} \mathrm{O}+\mathrm{V}^{5+}-\mathrm{OH}+\mathrm{V}^{4+}-\mathrm{OH} \\
2 \mathrm{~V}^{4+}-\mathrm{OH} \rightleftharpoons \mathrm{H}_{2} \mathrm{O}+\mathrm{V}^{3+}+\mathrm{V}=\mathrm{O} \\
\mathrm{O}_{2}+2 \mathrm{~V}^{3+} \rightarrow 2 \mathrm{~V}=\mathrm{O} \\
\mathrm{H}_{2} \mathrm{O}+\mathrm{V}^{5+}-\mathrm{OH} \rightleftharpoons \mathrm{V}^{5+}-\mathrm{OH}_{3} \mathrm{O}
\end{gathered}
$$

Reactions (1) (2) (4) (6) are reversible, reactions (3) (5) are irreversible, the reaction rate of each step can be described by Arrhenius's law. In the simulation of this paper, detailed reaction kinetics files was obtained by Chemkin, then the files were imported into FLUENT to calculate the solution.

\section{Boundary conditions and model simplified}

\subsection{Calculation method and boundary conditions}

The gas flow state of inlet is fully developed turbulence, the outlet condition of reactor is pressure-outlet. Using SIMPLE algorithm to establish pressure coupling of velocity, component transport equation, momentum equation and energy equation are calculated by using second order upwind scheme to improve the accuracy of results. The two layer catalysts are replaced by the porous medium model. The law of denitrification in BMCR operating mode was studied. The entrance boundary condition of the reactor was shown in table 3, The flue gas components were shown in table 4.

Tab.3 The entrance boundary condition of the reactor

\begin{tabular}{cc}
\hline name & value \\
\hline total flue gas flue $/\left(\mathrm{m}^{3} \cdot \mathrm{s}^{-1}\right)$ & 647.18 \\
Inlet velocity $/\left(\mathrm{m} \cdot \mathrm{s}^{-1}\right)$ & 5 \\
Inlet temperature $/ \mathrm{K}$ & 643 \\
equivalent diameter $/ \mathrm{m}$ & 11.15 \\
turbulent intensity $\%$ & 2.83 \\
\hline
\end{tabular}

Tab.4 Table of flue gas composition

\begin{tabular}{ccccccc}
\hline name & $\mathrm{CO}_{2}$ & $\mathrm{O}_{2}$ & $\mathrm{~N}_{2}$ & $\mathrm{H}_{2} \mathrm{O}$ & $\mathrm{SO}_{2}$ & NO \\
\hline Volume fraction & 0.1428 & 0.0332 & 0.7338 & 0.0892 & 0.0006 & 0.0004 \\
\hline
\end{tabular}

\subsection{Simplification and hypothesis of the model}

The following simplifications and assumptions were made in the model:

1) The internal components of the supporting rods and the supporting beams, which have little effect on the flow and denitrification reaction in the reactor were ignored.

2) The distribution of inlet velocity, concentration of components and temperature were considered to be uniform.

3 ) Do not consider the ammonia oxidation and other side reactions.

4) The effect of the fly ash on the flow was ignored.

\section{Validation of the model}

The rationality of the model was verified by comparing with the experimental data in paper[10]. The pore number of the catalyst is $4 \times 4$, the length is $5 \mathrm{~cm}$, the pitch is $11 \mathrm{~mm}$, the width of catalyst is $1 \mathrm{~mm}$, the specific surface area is $76.18 \mathrm{~m}^{2} / \mathrm{g}$, the porosity is 0.79 . The catalyst was also replaced by porous media model, and the model with grid division are shown in figure 4. 


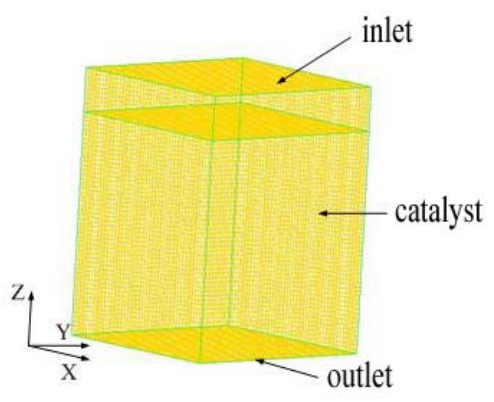

Fig.4 The model and mesh of catalyst

Simulation conditions are consistent with the experimental conditions: $\mathrm{NH}_{3} / \mathrm{NO}$ ratio is $1: 1$; $\varphi(\mathrm{NO})=1000 \mu \mathrm{L} / \mathrm{L} ; \quad \varphi\left(\mathrm{O}_{2}\right)=5 \%$; the balance air is nitrogen; the total flue gas flow is $200 \mathrm{~L} / \mathrm{h}$; the reaction temperature arrange from $250^{\circ} \mathrm{C}$ to $450^{\circ} \mathrm{C}$; the relationship between temperature and denitrification efficiency is shown in Figure 5.

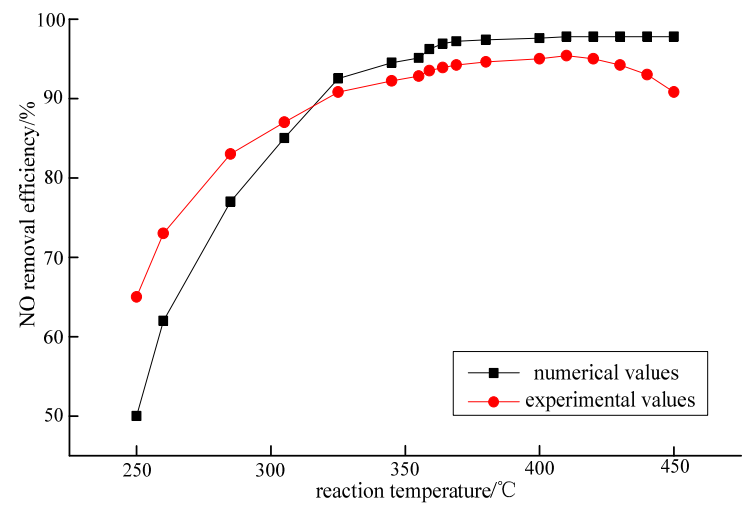

Fig.5 Results of Simulation

From figure 5 it can be seen that when the reaction temperature is blow $310^{\circ} \mathrm{C}$, the simulated values are significantly lower than the experimental values, the model is not accurate. However , the operating temperature of SCR is generally between $310 \sim 400{ }^{\circ} \mathrm{C}$, so when the reaction temperature in this range, the simulated values are slightly higher than the experimental values, because of the model does not take into account that the ammonia oxidation and other side reactions. When the temperature is higher than $420^{\circ} \mathrm{C}$, as the ammonia oxide sharply, so the denitrification efficiency become lower. In summary, the model was reasonable within the operating temperature of SCR.

\section{Simulation results and discussion}

\subsection{Distribution of flow field}

As there are two variable cross sections, therefore, even there are a lot of deflectors in the variable cross-section, the velocity distribution of Ammonia Injection Grid (AIG) section was still nonuniform, the relative deviation coefficient of velocity is $27.5 \%$, and there is a low velocity zone near the position of the variable cross section, as shown in figure 6 . Also the velocity distribution of AIG section influences the control of $\mathrm{AIG}^{[11]}$ 。

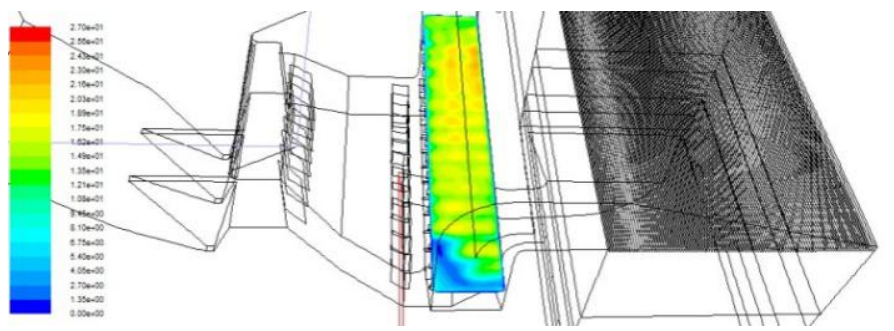

Fig.6 velocity distribution of AIG section 


\subsection{Partition strategy of AIG}

AIG is arranged a single layer in the reactor, include 240 spray nozzles in total, the shape of spray nozzles was cylindrical, the diameter is $0.03 \mathrm{~m}$. Each of the 8 nozzle was control by a branch, each pipe has a separate valve. There are two ammonia injection strategies of the power plant: 10 zones injection strategy and 30 zones injection strategy. The 10 zones injection strategy is each of the 24 nozzles for a partition, as shown in figure 8 .

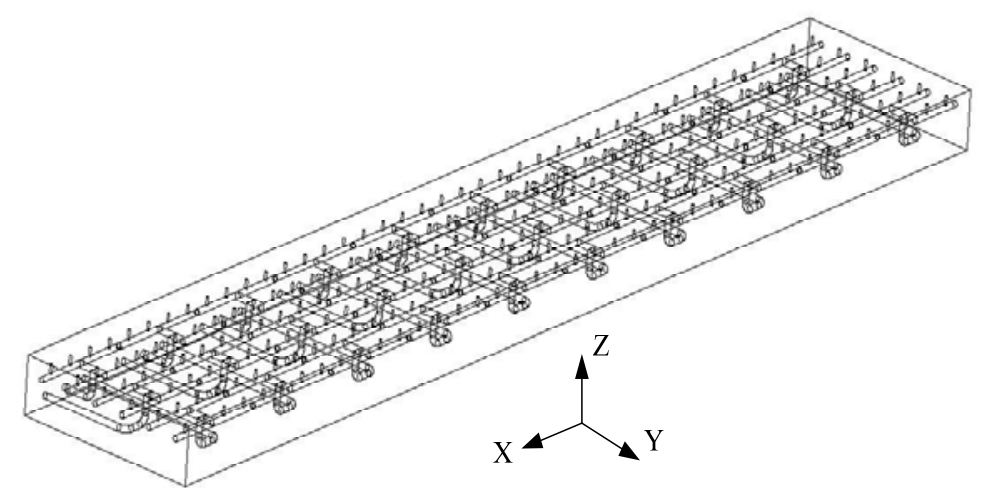

Fig.7 schematic diagram of AIG

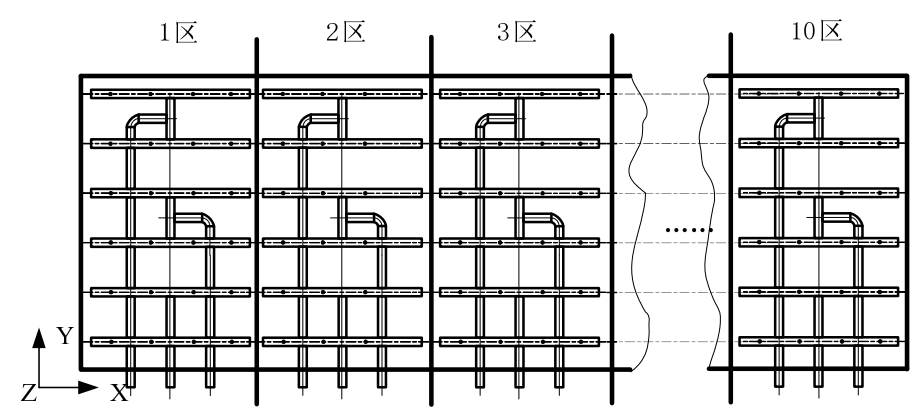

Fig.8 10 zones of ammonia injection

The 30 zones injection strategy for each of the 8 nozzles for a partition, as shown in figure 9 . With respect to 10 zones of ammonia injection strategy, the 30 zones of ammonia injection strategy enhanced the ammonia injection along the depth direction of flue.

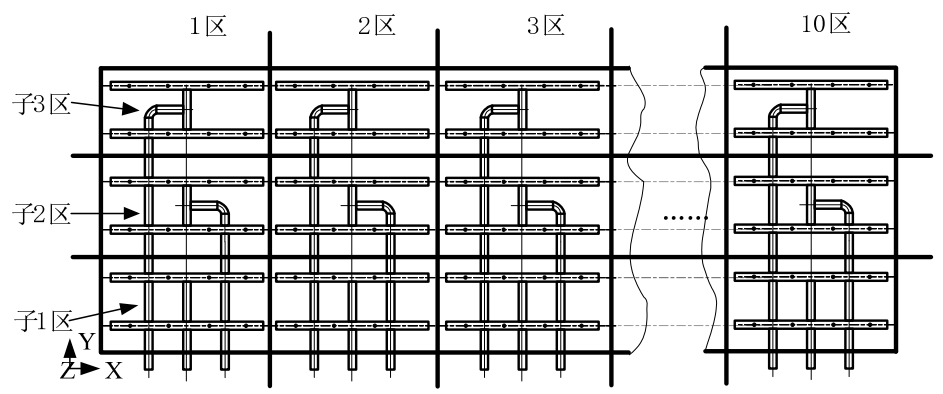

Fig.9 30 zones of ammonia injection

$\mathrm{NH}_{3} / \mathrm{NO}$ ratio set to be $0.8: 1$, the boundary conditions of both the 10 zones of the ammonia injection strategy and the 30 zones of ammonia injection strategy were calculated respectively. As shown in table 5 and table 6.

Table 5 The nozzle velocity of 10 zones ammonia injection

\begin{tabular}{ccccccccccc}
\hline Partition number & zone 1 & zone 2 & zone 3 & zone 4 & zone 5 & zone 6 & zone 7 & zone 8 & zone 9 & zone 10 \\
\hline velocity & 13.5 & 14.5 & 17.11 & 17.08 & 16.17 & 15.78 & 15.0 & 14.06 & 13.53 & 2.85 \\
\hline
\end{tabular}


Table 6 The nozzle velocity of 30 zones ammonia injection

\begin{tabular}{ccccccccccc}
\hline Partition number & zone & zone2 & zone & zone & zone & zone & zone & zone & zone & zone \\
& 1 & & 3 & 4 & 5 & 6 & 7 & 8 & 9 & 10 \\
\hline velocity of partition 1 & 13.1 & 12.48 & 13.93 & 14.22 & 13.93 & 14.05 & 13.77 & 13.13 & 11.03 & 0 \\
velocity of partition 2 & 13.46 & 14.57 & 17.6 & 17.49 & 16.79 & 16.31 & 15.54 & 14.63 & 14.42 & 2 \\
velocity of partition 3 & 13.93 & 16.45 & 19.79 & 19.53 & 17.8 & 16.99 & 15.7 & 14.43 & 15.15 & 6.54 \\
\hline
\end{tabular}

\subsection{Simulation of denitration law}

The model was assumed two layer catalysts just put into operation, the relative deviation coefficient of $\mathrm{NH}_{3} / \mathrm{NO}$ ratio at inlet of the first layer catalyst was $8.9 \%$ by using the method of 10 zones injection strategy, the denitrification efficiency is $79.65 \%$, the volume fraction of the ammonia escape at the outlet reactor is $1.4 \times 10^{-6}$, the denitrification efficiency of the first layer catalyst is $75 \%$, the volume fraction of ammonia is $2.0 \times 10^{-5}$ at outlet. The distribution of ammonia volume fraction in the reactor is shown in Figure 10.
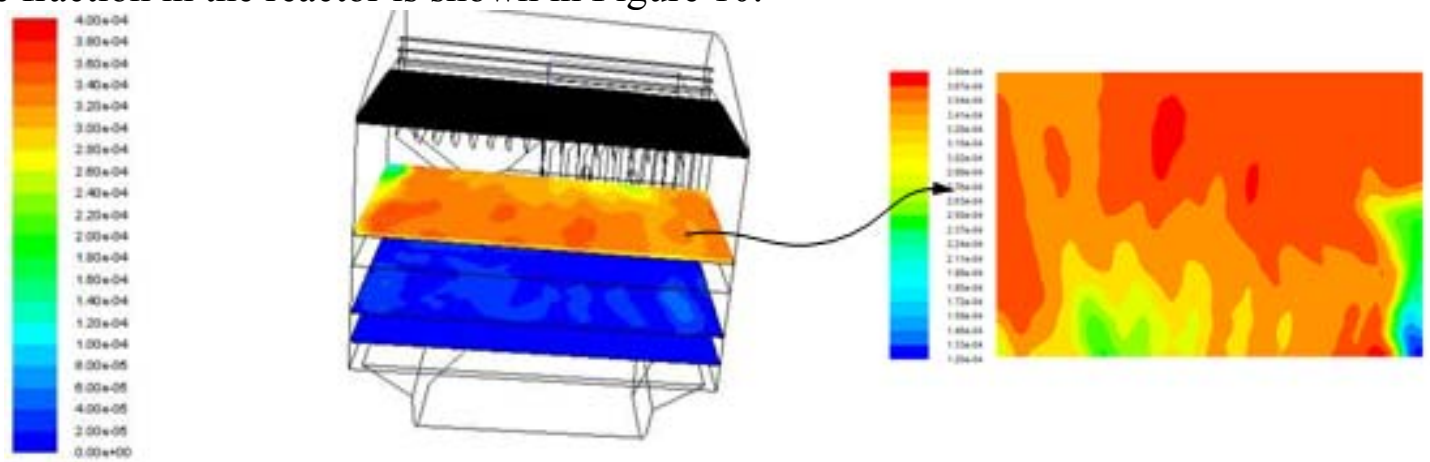

Fig.10 volume fraction of ammonia in the reactor

Through simulation, for SCR catalysts just put into operation, the denitrification reaction was basically completed in the first layer catalyst, the second layer catalyst mainly plays a role in the absorption of ammonia.

The relative deviation coefficient of $\mathrm{NH}_{3} / \mathrm{NO}$ ratio was $5.6 \%$ at the inlet of first layer catalyst by using 30 zones injection strategy, although the uniformity of $\mathrm{NH}_{3} / \mathrm{NO}$ ratio is improved, when compared with 10 zones ammonia injection strategy. But the results of denitrification efficiency and the ammonia slip are the same. The main reason is , for the catalyst just put into operation with high denitration performance, so when the $\mathrm{NH}_{3} / \mathrm{NO}$ ratio is not very high, the good effect of denitrification efficiency can be maintained. The distribution of ammonia volume fraction in the reactor is shown in Figure 11.
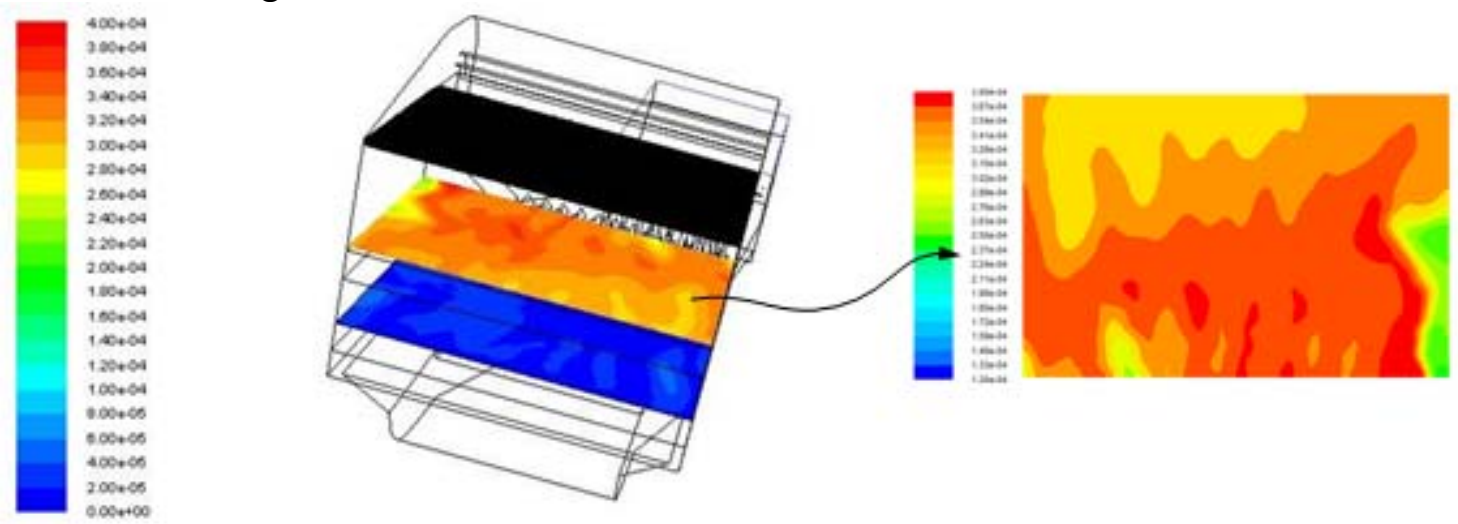

Fig.11 ammonia distribution of each section in reactor

Due to the SCR reactor was arranged in the high dust section, so for the catalysts operation for a period of time will inevitably be influenced by fly ash, such as blockage, wear and poisoning of catalyst. In this paper, the effects of poisoning on the properties of the catalyst are not considered, the effect of plug and wear of catalyst on the reaction were taken into consideration. The wear of the 
catalyst can reduce the contact area between the gas and the catalyst, it was assumed that the specific surface area of the first layer catalyst is reduced from $200 \mathrm{~m}^{2} / \mathrm{m}^{3}$ to $299 \mathrm{~m}^{2} / \mathrm{m}^{3}$, the specific surface area of the second layer catalyst also the kinetic parameters of the two layer catalyst are unchanged. The denitrification efficiency is $78.6 \%$ when using 10 zones injection strategy, the volume fraction of ammonia at outlet is $5.6 \times 10^{-6}$, the denitrification efficiency of the first layer catalyst is $57.5 \%$, the volume fraction of ammonia at outlet is $9.0 \times 10^{-5}$. The distribution of ammonia volume fraction at horizontal direction $\mathrm{X}=4 \mathrm{~m}$ in the reactor was shown in figure 12 .

The denitrification efficiency is $78.7 \%$ when using 30 zones injection strategy, the volume fraction of ammonia at outlet is $5.2 \times 10^{-6}$, Denitrification efficiency of the first layer catalyst is $58 \%$, the volume fraction of ammonia at outlet is $8.8 \times 10^{-5}$. The distribution of ammonia volume fraction at horizontal direction $\mathrm{X}=7 \mathrm{~m}$ in the reactor was shown in figure 13 .

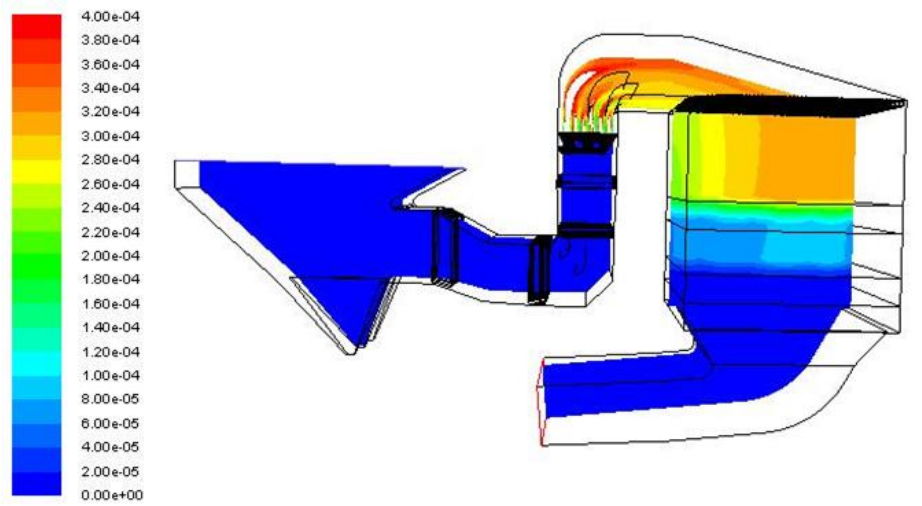

Fig.12 ammonia volume fraction at $\mathrm{X}=4 \mathrm{~m}$

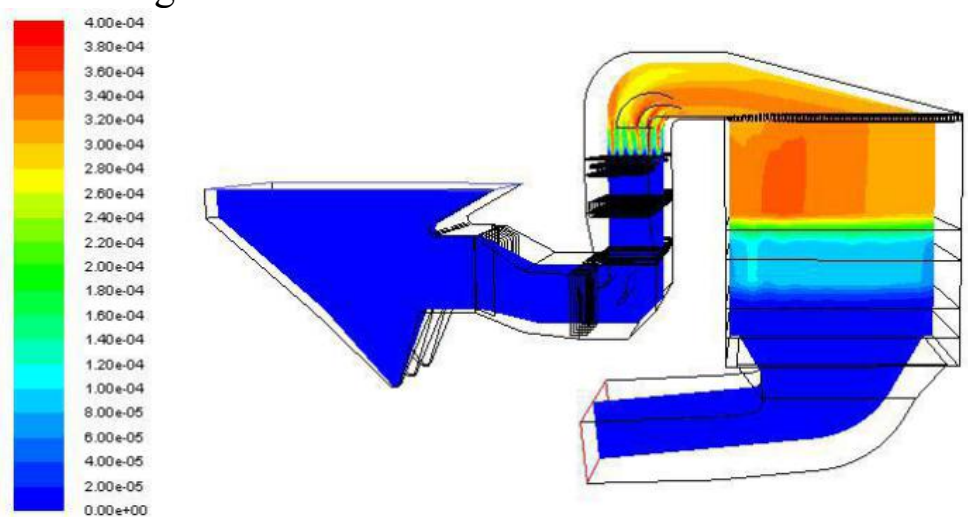

Fig.13 ammonia volume fraction at $\mathrm{X}=7 \mathrm{~m}$

Through simulation, it can be seen that when the denitrification efficiency of first layer catalyst decreased, the denitrification efficiency was almost the same no matter using 10 zones ammonia injection strategy or using 30 zones ammonia injection strategy. There are two reasons : on the one hand, the distribution of ammonia becomes more uniform, the denitrification efficiency of low ammonia concentration region become higher, but the denitrification efficiency of high ammonia concentration region become lower; on the other hand, the average residence time of the flue gas in the catalyst remains unchanged, it does not have enough time to complete the reaction. So in the case of $\mathrm{NH}_{3} / \mathrm{NO}$ ratio is not very high, an ideal denitrification effect can be gained when the relative deviation coefficient of $\mathrm{NH}_{3} / \mathrm{NO}$ ratio can be controlled in $10 \%$.

\section{Summary}

A three-dimensional SCR numerical model of 660MW coal fired unit was established by FLUENT coupled with detailed reaction kinetics, the influence of factors such as the specific surface area and the strategy of ammonia injection on the reaction was studied, it can be concluded 
that:

(1)The distribution of velocity at AIG section was not uniform, because there exits two cross sections in the reactor, and the relative deviation coefficient of velocity is $27.5 \%$.

(2)For SCR catalysts just put into operation, the denitrification reaction was completed basically in the first layer catalyst, the second layer catalyst mainly plays a role in the absorption of ammonia, the same denitrification efficiency was gained no mater using 30 zones or 10 zones ammonia injection strategy.

(3)When the catalysts were put into operation after a period of time, denitrification efficiency become lower also the ammonia slip at outlet become higher. At this point, the 30 zones ammonia injection strategy is slightly better than 10 zones ammonia injection strategy.

\section{References}

[1].SUN Keqin, ZHONG Qin. Flue gas denitrification technology and engineering application of thermal power plant[M], Beijing: Chemical Industry Press, 2006（in Chinese）.

[2].ZHANG Qiang. Flue gas denitrification technology and engineering application of coal fired power plant SCR [M]. Beijing: Chemical Industry Press，2007（in Chinese）.

[3].ZHU Tianyu, LI Debo, FANG Qingyan, et al. Flow Field optimization for SCR system of coal-fired power plant[J]. Journal of Chinese society of power engineering, 2015, 35 (246): 481-488.

[4].YANG Song, DING Haomei, HUANG Yue. Numerical simulation and optimization of flow field in an SCR system [J]. Thermal power generation , 2014, 43 (9) : 71-75.

[5].LEI Z G, LIU X Y, JIA M R. Modeling of Selective Catalytic Reduction （SCR） for NO Removal Using Monolithic Honeycomb Catalyst [J]. Energy\&Fuels 2009, 23 (12) :6146-6151.

[6].LING Zhongqian, ZENG Xianyang, HU Shantao, et al. Numerical Simulation on optimization of SCR Denitrification System for coal-fired boilers[J]. Journal of Chinese society of power engineering, 2014, 34 (1) :50-56.

[7].LEI Da, JIN Baosheng. 3-D Numerical Model of a Power Station SCR System Based on Heterogeneous Reaction [J].Journal of Combustion Science and Technology, 2010, 16 (3): 236-240.

[8].Dumesic J A, Topsoe N Y, Topsoe H, et al. Kinetics of selective catalytic reduction of nitric oxide by ammonia over Vanadia/Titania[J]. Journal of catalysis, 1996, 160 (2) : 409-417.

[9].Tronconi E, Nova I, Ciardelli C, et al. Redox features in the catalytic kinetics of the "stand" and "fast" $\mathrm{NH}_{3}-\mathrm{SCR}$ of $\mathrm{NO}_{x}$ over a V-based catalyst investigated by dynamic method [J]. Journal of catalysis, 2007, 245(1):1-10.

[10].ZHU Chongbing, JIN Baosheng, LI Feng, et al. Study on De-NO $\mathrm{x}_{\mathrm{x}}$ performance of Honeycomb $\mathrm{V}_{2} \mathrm{O}_{5}-\mathrm{WO}_{3} / \mathrm{TiO}_{2}$ Catalyst [J]. Proceedings of the CSEE,2007, 27 (29) : 45-50.

[11].LEI Da, JIN Baosheng. The influence of flue gas velocity field of AIG for the uniform flow and reducing agent mixing performance of efficient SCR[J]. Journal of engineering for thermal energy and power, 2009, 24 (1):113-119. 